\title{
A new parameter in multiple myeloma: CYP3A4*1B single nucleotide polymorphism
}

\author{
Istemi Serin ${ }^{1}$ (D) - Sacide Pehlivan ${ }^{2} \cdot$ Ilknur Gundes ${ }^{3} \cdot$ Yasemin Fidan Oyaci $^{2} \cdot$ Mustafa Pehlivan $^{4}$
}

Received: 3 October 2020 / Accepted: 3 November 2020 / Published online: 10 November 2020

(C) Springer-Verlag GmbH Germany, part of Springer Nature 2020

\begin{abstract}
Multiple myeloma $(\mathrm{MM})$ is a disease caused by malignant plasma cells, causing free light chain release accompanying the increase in monoclonal immunoglobulin. Cytochrome P450 (CYP) is one of the large and functional enzyme families composed of various hemoproteins. This protein network has been shown to play a role in many treatment steps in current practices. We aimed to investigate the relationship between genotypes of CYP3A4*1B and treatment response and prognosis of MM. Seventytwo patients diagnosed with MM between January 2016 and 2020 and 100 healthy people to create a control group participated in our study. Genotypes were classified in 3 separate groups as NN, MN, and MM. Both PFS and OS were significantly higher in the NN genotype $(p=0.001, p=0.014)$. Being under the age of 65 was 27.988 times more protective for OS and 4.496 times for PFS $(p=0.006, p=0.017)$. NN genotype was shown to be 41.666 -fold protective for OS and 3.144-fold protective for PFS $(p=$ $0.004, p=0.030$ ). This study demonstrated that CYP3A4*1B NN genotype, which is an important cytochrome $\mathrm{p} 450$ member for the treatment of MM, was 41.666-fold protective for OS and 3.144-fold protective for PFS. It was shown in this study for the first time in the literature as a valuable contribution.
\end{abstract}

Keywords Multiple myeloma $\cdot$ P450 $\cdot$ CYP3A4B $\cdot$ Prognosis $\cdot$ Treatment

\section{Introduction}

Multiple myeloma (MM) constitutes approximately $10 \%$ of hematological malignancies. It is a disease caused by malignant plasma cells, the pathology of which is abnormal proliferation, causing free light chain release accompanying the increase in monoclonal immunoglobulin [1]. Studies show that its prevalence is around 7 in 100,000 people, and the median age is 65 [2-4]. Clinical manifestations appear as renal failure, anemia, hypercalcemia, and lytic bone lesions.

Istemi Serin

serinistemi@hotmail.com

1 Department of Hematology, Istanbul Training and Research Hospital, University of Health Sciences, Fatih, Istanbul, Turkey

2 Department of Medical Biology, Faculty of Medicine, Istanbul University, Istanbul, Turkey

3 Department of Internal Medicine, Faculty of Medicine, Gaziantep University, Gaziantep, Turkey

4 Department of Hematology, Faculty of Medicine, Gaziantep University, Gaziantep, Turkey
Although positron emission tomography/computed tomography $(\mathrm{PET} / \mathrm{CT})$ is often preferred for the detection of lytic bone lesions, magnetic resonance (MR), computed tomography (CT), and direct radiographs also contribute to the diagnosis.

Cytochrome P450 is one of the large and functional enzyme families composed of various hemoproteins. While it was initially thought that "p 450 " was a single cytochrome found only in the liver and its role was to process drugs and other synthetic exogenous substances, this protein network has been shown to play a role in many treatment steps in current practices [5]. The $\mathrm{P} 450$ family is subdivided according to the amino acid similarity between them, arranged in a way that it helps families and subfamilies according to the percentage of amino acid similarity. When the similarity is $40 \%$ and above, the same digit subfamily is also grouped; $55 \%$ and above are grouped in a certain subfamily formed with the same letter [6,7]. Human genome consists of 18 different types of p450 families. It is seen that this family has subfamilies consisting of 41 separate, different, variety proteins encoded by 57 genes. It is classified as an individual gene/isoenzyme/isozyme/isoform. For example, CYP1A1 refers to CYP family 1 , subfamily A, and protein 1 in a subfamily. Gene and cDNA are written in italics (CYP1A1), while 
mRNA and protein are shown in the normal uppercase font (CYP1A1) [8, 9].

The cytochrome p450 system (CYP) is divided into two main classes: those involved in the detoxification of xenobiotics and those involved in the biosynthesis of endogenous compounds [9]. CYPs are mainly monooxygenases that mediate hydroxylation and oxidation reactions that increase the hydrophilicity of CYP substrates. This results in either the activation of prodrugs or the increased clearance and excretion of chemotherapeutic agents by the kidneys. CYP has a great role in the metabolism of chemotherapeutics. Approximately $80 \%$ of all therapeutic drugs are mainly metabolized by members of the CYP1, CYP2, or CYP3 families, and $50 \%$ of this percentage is metabolized only by members of the CYP3A subfamily [10]. The human locus for the CYP3A gene cluster is located on chromosome 7q21-q22. It consists of two pseudogenes (CYP3AP1 and CYP3AP2) and four genes (CYP3A4, CYP3A5, CYP3A7, and CYP3A43). Each of the four functional genes in the CYP3A locus contains 13 exons [11].

CYP3A4 is the most studied isoform in the CYP3A subfamily and is found predominantly in the small intestine and adult liver. It is responsible for most of the metabolic activities attributed to the CYP3A subfamily [10-12]. CYP3A4 and CYP3A5 expression levels are comparable in many cancers, higher than non-tumor tissues $[10,13]$. This leads them to be seen as the target of chemotherapeutic and other anticancer mechanisms. An important factor influencing CYP3A4 expression and activity is the presence of single nucleotide polymorphisms (SNPs). SNPs are genetic differences in which a position in a gene is occupied by different nucleotides and each resulting variation is within the population. The biological results of some SNPs can cause sharp variations in enzyme expression and activity. This can lead to differences in drug response, toxicity, bioavailability, and clearance among patients. We can see in the literature that CYP3A4*1B is reported to be present in men with more advanced prostate cancer [14].

In our study, we aimed to investigate the relationship between genotypes of CYP3A4*1B and MM and to investigate the effects of treatment response and prognosis.

\section{Material and methods}

Seventy-two patients diagnosed with MM who were diagnosed in XXX University Faculty of Medicine, Hematology Clinic between January 2016 and 2020, as well as 100 people without any comorbidity in order to create a healthy control group participated in our study. In addition to the demographic data of the patients, such as age and gender, initial DurieSalmon Stages, International Prognostic Index (IPI) scores, Eastern Cooperative Oncology Group (ECOG) scores, laboratory data (hemoglobin, leukocyte, platelet, C-reactive protein (CRP), lactate dehydrogenase (LDH), beta 2 microglobulin, albumin), first-line treatment preference, overall survival (OS) and progression-free survival (PFS) data, mortality rates, and mean follow-up durations (months) were recorded. The study began by obtaining the approval of the XXX University Ethics Committee (07-2007/40).

All patients were given 4 cycles of bortezomib $1.3 \mathrm{mg} / \mathrm{m} 2 /$ week subcutaneously, cyclophosphamide $300 \mathrm{mg} / \mathrm{m}^{2} /$ week intravenously, and dexamethasone $40 \mathrm{mg} /$ week orally; D 18-15-22 (VCD) and all have been through autologous stem cell transplantation (ASCT). Lenalidomide was followed by $10 \mathrm{mg} /$ day D1-21, dexamethasone $40 \mathrm{mg} /$ week orally, and 24 months (LD) as a maintenance treatment. The patients were divided into two groups, aged under 65 and over 65 , and statistically evaluated in terms of PFS and OS.

CYP3A4*1B genotyping was performed for the patient and the healthy control group. Genotypes were classified in 3 separate groups as NN, MN, and MM [14]. Significant differences in PFS and OS between both genotypes were analyzed statistically.

In addition, first-line rescue regimens of the patients after progression were examined. Among these regimens, pomalidomide $4 \mathrm{mg}$ /day orally; dexamethasone $40 \mathrm{mg} /$ week orally (PD) and carfilzomib $20 \mathrm{mg} / \mathrm{m} 2$ intravenously days 1 and 2; if tolerated escalated dose to $27 \mathrm{mg} / \mathrm{m} 2$ on days $8,9,15$, 16; and dexamethasone $40 \mathrm{mg}$ /week orally $(\mathrm{Cd})$, the number and percentages of patients and the CYP3A4*1B genotype distribution were also analyzed statistically.

Blood samples were taken into EDTA tubes and stored at $-20{ }^{\circ} \mathrm{C}$. DNAs were isolated from the collected blood samples by using the GeneMark isolation kit. The forward and reverse primers (rs2740574) were prepared for PCR amplification of CYP3A4 gene 5' promoter region. Then CYP3A4 genes were amplified with PCR from isolated genomic DNAs. The replication material (PCR product) was containing the polymorphic region for Mboll (270 bp). Cutting products were analyzed by using uncut PCR products and DNA ladder in 3\% agarose gel electrophoresis. Homozygous wild-type DNA (genotype: $\mathrm{M}+\mathrm{M}+$ ) produced $175 \mathrm{bp}$ and $169 \mathrm{bp}$ alleles, the homozygous variant type (genotype: $\mathrm{M}-/ \mathrm{M}-$ ) produced $210 \mathrm{bp}$ and $175 \mathrm{bp}$ alleles, and heterozygote genotype (genotype $\mathrm{M}+/ \mathrm{M}-$ ) was recognized by showing $210 \mathrm{bp}$, $175 \mathrm{bp}$, and $169 \mathrm{bp}$ fragments in electrophoresis [14].

Statistical analysis SPSS for Windows (version 13.0; SPSS, Chicago, IL) software was used for data analysis. Logistic regression analysis was used to determine the statistical significance of the differences between control groups and patients. The odds ratios (OR) and $95 \%$ confidence intervals were used for this analysis. The X2 test was used to compare the differences between the patient and the control group's global and APC 2 promotor methylation results. Fisher's test was used if necessary. $p$ values $<0.05$ were considered to indicate statistical 
Table 1 Clinical features and treatment regimens of MM patients

\begin{tabular}{|c|c|c|c|c|c|c|}
\hline & & $\begin{array}{l}\text { Multiple myeloma } \\
\text { Median }\end{array}$ & $n^{\mathrm{a}}(\%)$ & $\begin{array}{l}\text { Control } \\
\text { Median }\end{array}$ & $\begin{array}{l}\text { Control } \\
n^{\mathrm{b}}(\%)\end{array}$ & $p$ \\
\hline Age & & $54(29-72)$ & & $53(32-68)$ & & $0.917 *$ \\
\hline Gender & Female/male & & $36 / 36(50 / 50)$ & & $45 / 55(45 / 55)$ & $0.355^{\&}$ \\
\hline \multirow[t]{2}{*}{ Subtypes } & Kappa/lambda & & $36 / 15(70.6 / 29.4)$ & & & \\
\hline & Light chain & & $5(10)$ & & & \\
\hline \multicolumn{7}{|l|}{ Stage (Durie-Salmon) } \\
\hline & $\mathrm{A} / \mathrm{B}$ & & $41 / 9(82 / 18)$ & & & \\
\hline \multirow[t]{2}{*}{ IPI } & I & & $14(28.6)$ & & & \\
\hline & II/III & & $12 / 23(24.5 / 46.9)$ & & & \\
\hline ECOG & $>1$ & & $9(12.5)$ & & & \\
\hline Hemoglobin & $\mathrm{gr} / \mathrm{dL}$ & $10.6(6.6-15)$ & & & & \\
\hline Leukocyte & $\mu \mathrm{L}$ & $6640(2760-17,330)$ & & & & \\
\hline Trombocyte & $10^{3} / \mu \mathrm{L}$ & $123(69-330)$ & & & & \\
\hline C-reactive protein & $\mathrm{mg} / \mathrm{dL}$ & $5.2(2.1-125)$ & & & & \\
\hline $\mathrm{LDH}$ & $\mathrm{IU} / \mathrm{L}$ & $214(100-434)$ & & & & \\
\hline b2-mikroglobulin & $\mathrm{mg} / \mathrm{L}$ & $4.1(1.5-48)$ & & & & \\
\hline Albumin & $\mathrm{gr} / \mathrm{L}$ & $3.6(1.1 .6-5.1)$ & & & & \\
\hline Treatment & VCD, ASCT, LD & & & & & \\
\hline OS (months) & & $(88)$ & & & & \\
\hline PFS (months) & & $(55)-69.3$ & & & & \\
\hline Relapse & & & $23(31.9)$ & & & \\
\hline Mortality & & & $6(8.3)$ & & & \\
\hline Follow-up (months) & & $24.3(4.1-155.2)$ & & & & \\
\hline
\end{tabular}

$n^{\mathrm{a}}=72 ; n^{\mathrm{b}}=100 ; *^{*}$ median test, ${ }^{\&}$ Pearson chi-square

**PFS progression-free survival, $O S$ overall survival, IPI International Prognostic Index, ISS International Scoring System, ECOG Eastern Cooperative Oncology Group, $L D H$ lactate dehydrogenase, $C R P$ C-reactive protein, $V C D$ bortezomib, cyclophosphamide, dexamethasone, $A S C T$ autologous stem cell transplant, $L D$ lenalidomide, dexamethasone

significance. The Kaplan-Meier method was used to estimate the survival probabilities and the log-rank test to compare differences. The significance of risk factors was confirmed by applying the Cox stepwise regression analysis. In the multivariate analysis, the stepwise (backward) eliminated variables were used with a significance of less than $10 \%$.

\section{Results}

Of the 72 patients included in our study, 36 were female $(50 \%)$ and 36 were male $(50 \%)$. The median age of the patient group was 54 (range, 29-72). Looking at the disease subtypes, only 5 patients $(10 \%)$ were diagnosed as light chain MM. All patients received the same treatment. The median PFS of the patients was 55, and the median OS was 88 months. There was no significant difference in age and gender breakdowns between the patient and the healthy control group ( $p=0.917, p=0.355$ ). Mortality was $8.3 \%$ with 6 patients. The average follow-up period was 24.3 months (range, 4.1-155.2) (Table 1).
Fifty-six of the patients had a genotype "CYP3A4*1B NN" (77.8\%), 15 of them "MN" (20.8\%), and 1 of them had "MM" (1.4\%). There was no significant difference between the genotypes between the patient group and healthy controls (NN, $p=0.435 ; \mathrm{MN}, p=0.272 ; \mathrm{MM}, p=0.365)$. In terms of allele, the $\mathrm{N}$ allele was $127(88.2 \%)$, and the $\mathrm{M}$ allele was 17 (11.8\%). There was no significant difference between the patient group and the healthy control group $(p=0.864)$ (Table 2).

Considering the univariate analysis performed to evaluate prognostic factors in terms of PFS and OS (log-rank), OS was found to be significantly higher in patients under 65 years of age compared to patients aged 65 and over $(p=0.001)$. For ISS III, OS was significantly lower $(p=0.019)$. There was no significant difference in terms of PFS $(p=0.086)$. Both PFS and OS were significantly higher in the CYP3A4*1B NN genotype. $(p=0.001, p=0.014)$ (Table 3 ).

Looking at the preferred first-line rescue regimens and distribution after progression, the preference rate for PD was significantly higher in the NN genotype group than in the $\mathrm{MN} / \mathrm{MM}$ group $(p=0.014)$ (Table 4$)$. 
Table 2 Comparison of frequencies of CYP $3 \mathrm{~A} 4 * 1 \mathrm{~B}$ gene variants between patients with multiple myeloma and healthy controls

\begin{tabular}{lllllll}
\hline CYP3A4*1B & Genotype & $\begin{array}{l}\text { Multiple } \\
\text { myeloma }\end{array}$ & $\begin{array}{l}\text { Healthy } \\
\text { control }\end{array}$ & $\begin{array}{l}\text { OR } \\
\text { Exp(B) }\end{array}$ & $95 \%$ CI & $p$ \\
\hline $\begin{array}{l}\text { Genotypes } \\
\text { CYP3A4*1B }\end{array}$ & NN & $\begin{array}{l}n={ }^{\mathrm{a}}(\%) \\
56(77.8)\end{array}$ & $\begin{array}{l}n=100(\%) \\
83(83)\end{array}$ & $0.717^{\&}$ & $0.335-1.536^{\&}$ & $0.435^{*}$ \\
& $\mathrm{MN}$ & $15(20.8)$ & $13(13)$ & $0.628^{*}$ & $0.274-1.440^{*}$ & $0.272^{*}$ \\
& $\mathrm{MM}$ & $1(1.4)$ & $4(4)$ & $2.809^{*}$ & $0.300-26.262^{*}$ & $0.365^{*}$ \\
Allele & & & & & \\
& $\mathrm{N}$ & $127(88.2)$ & $179(89.5)$ & & & \\
& $\mathrm{M}$ & $17(11.8)$ & $21(10.5)$ & $0.923^{\&}$ & $0.471-1.809^{\&}$ & $0.864^{\&}$ \\
\hline
\end{tabular}

${ }^{\mathrm{a}} n=72, * \mathrm{OR}(95 \% \mathrm{CI})$ was adjusted by age and sex, ${ }^{\&}$ Fisher's exact test.
In the multivariate regression analysis (Cox regression), there was no significant difference in OS and PFS in terms of IPI ( $p=0.191, p=0.850)$. Being under the age of 65 was 27.988 times more protective for OS and 4.496 times for PFS $(p=0.006, p=0.017)$. CYP3A4*1B NN genotype was shown to be 41.666-fold protective for OS and 3.144-fold protective for PFS ( $p=0.004, p=0.030$ )(Table 5, Fig. 1, Fig. 2).

\section{Discussion}

Besides studies showing that CYP3A4 is higher in tumor tissues and examining its role in carcinogenesis and propagation, it should be said that its role in treatment and response is quite meaningful [5]. In studies on CYP3A4, we see that many gene rearrangements are mentioned. Similarly, polymorphism-drug responses are among the topics of these publications.

CYP3A4*1A, which is the wild-type allele of CYP3A4, is seen predominantly in the general population. The first discovered SNP variant CYP3A4*1B (rs2740574; A > G substitution in $5^{\prime}$ promoter region) is seen as another SNP in $66 \%$ of the African-American community, in $4 \%$ of Europeans, but it is not seen in Asians [12]. CYP3A4*1B is generally seen in men and is detected in more advanced stages of prostate cancer [15]. This paved the way for its investigation in other solid tumors. The liver p450 system mainly metabolizes cyclophosphamide, ifosfamide, dacarbazine, procarbazine, tegafur, and thiotepa.

CYP3A4 is involved in the metabolism of various anticancer agents (taxanes, vinca alkaloids, and drugs such as imatin$\mathrm{ib}$, gefitinib, sorafenib). It enables docetaxel to be inactivated by converting to its hydroxylated derivatives. A high
Table 3 Univariate analysis ( $\log$ rank test) of prognostic factors

\begin{tabular}{lllllll}
\hline & $N$ & OS & Log-rank $p$ value & $\begin{array}{l}\text { PFS } \\
\text { Mo* }\end{array}$ & Log-rank $p$ value \\
& & & & & \\
& & 72 & $(88)$ & & $69.3 /(55)$ & \\
Gender & Female/male & $36 / 36$ & $87 / 88$ & 0.972 & $86.7 / 55.3$ & 0.176 \\
Age & $<65>65$ & $51 / 11$ & $92 / 51$ & $\mathbf{0 . 0 0 1}$ & $89.6 /(52)$ & 0.071 \\
IPI (ISS) & $I$ & 14 & 100 & & 69.3 & \\
& II & 12 & 88 & & $(64)$ & \\
& III & 23 & 69 & $\mathbf{0 . 0 3 4}$ & 52.7 & 0.150 \\
IPI (ISS) & I/II & 26 & 95 & & $(59)$ & \\
& III & 23 & 69 & $\mathbf{0 . 0 1 9}$ & 52.7 & 0.086 \\
ECOG & $\leq 1>1$ & $40 / 9$ & $89 / 80$ & 0.577 & $69.3 /(71)$ & 0.725 \\
CRP (mg/L) & $<5>5$ & $23 / 24$ & $89 / 87$ & 0.662 & $(54) / 89.6$ & 0.375 \\
Treatment & VCD, ASCT, LD & 72 & 88 & & & \\
CYP3A4*1B & NN & 56 & 97 & & 89.6 & \\
& MN/MM & 16 & 53 & $\mathbf{0 . 0 0 1}$ & 20.4 & $\mathbf{0 . 0 1 4}$ \\
\hline
\end{tabular}

Data written in bold was found to be statistically significant $(p<0.05)$

**PFS progression-free survival, OS overall survival, IPI International Prognostic Index, ISS International Scoring System, ECOG Eastern Cooperative Oncology Group, $C R P$ C-reactive protein, $V C D$ bortezomib, cyclophosphamide, dexamethasone, $A S C T$ autologous stem cell transplant, $L D$ lenalidomide, dexamethasone 
Table 4 Patient distribution based on rescue regimens

\begin{tabular}{llllll}
\hline & & Regimen & $n$ & $\%$ & $p$ \\
\hline CYP3A4*1B & \multirow{2}{*}{ NN } & Cd & 12 & $21.4 \%$ & \\
& & PD & 44 & $78.6 \%$ & \\
& MN/MM & Cd & 7 & $43.7 \%$ & \\
& & PD & 9 & $56.3 \%$ & $\mathbf{0 . 0 1 4}$ \\
\hline
\end{tabular}

Data written in bold was found to be statistically significant $(p<0.05)$

**PD pomalidomide, dexamethasone, $C d$ carfilzomib, dexamethasone

CYP3A4 activity will result in poor therapeutic efficacy of the drug. Therefore, a $49 \%$ reduction in docetaxel clearance was observed in cancer patients treated with docetaxel in combination with the active CYP3A4 inhibitor ketoconazole [16].

CYPA3A4 mainly plays a role in the metabolism of drugs such as nitroarene, triazole, heterocyclic amine, azoaromatic amine, N-heterocyclic aromatic hydrocarbon, dibenzocarbazole, estradiol derivative; estrogen, contraceptive, nitrosamine, and triphenylethyleneamine and also plays a role in the metabolism of drugs such as antiestrogens and estrogen receptor modulators [5, 17]. Apart from this group of drugs, bexarotene, busulfan, cisplatin, cyclophosphamide, cytarabine, docetaxel, doxorubicin, etoposide, ifosfamide, imatinib mesylate, tretinoin, vinblastine, vincristine, and vinorelbine are also involved in the mechanism of chemotherapeutics, which are widely used in hematological malignancies. However, we see that the literature data are limited especially in terms of treatment responses with OS and PFS. In this context, it is possible to say that the data presented for the first time in the literature were detected in our study. Examining the literature data between the treatments of the patients included in our study and their relationship with $\mathrm{p} 450$ seems important in terms of explaining the significant differences we obtained in terms of OS and PFS. It is necessary to mention the publications on the relationship between bortezomib, cyclophosphamide, dexamethasone, lenalidomide, and the p450 enzyme system and melphalan used in ASCT [18-22].

Bortezomib, the main drug of the patient group in our study, undergoes extensive metabolism by hepatic microsomal
CYP3A4 and CYP2C19 enzymes [18]. Therefore, the coadministration of potent inhibitors and inducers of these enzymes has a significant effect on the efficacy and elimination of bortezomib. In an important study, co-administration of ketoconazole, a potent CYP3A4 inhibitor, has been shown to increase the mean bortezomib exposure by $35 \%$ in patients. Hellman et al. [19], the effects of co-administration of dexamethasone, a weak CYP3A4 inducer and rifampin or rifampicin, a strong CYP3A4 inducer, on the pharmacokinetics and safety of bortezomib in patients with $\mathrm{MM}$ and NHL were evaluated. Co-administration of rifampicin resulted in a $45 \%$ decrease in bortezomib concentration, while concurrent administration of dexamethasone had no significant effect. The results of these two important studies are also very guiding for our study. Considering that the effect of dexamethasone used with bortezomib is not significant, our SNP findings in the CYP3A4 system may be thought to be closely related to bortezomib.

Cyclophosphamide is included in the treatment of our patient group as a commonly used chemotherapeutic. It is converted into active metabolites via CYP3A4 and excreted renally. In a study conducted in this context, similar to the bortezomib study, the use of cyclophosphamide together with the CYP3A4 inhibitor ketoconazole causes a decrease in toxic products formed by the activation of cyclophosphamide [20].

Melphalan, on the other hand, does not need any activation to show its toxicity. It has a half-life of $75 \mathrm{~min}$ in vivo and is mostly excreted in the urine. Melphalan is eliminated by both renal excretion and spontaneous chemical degradation to its mono- and di-hydroxy metabolites. Therefore, no relationship has been described between the p450 system and melphalan activity [21, 22]. Studies on lenalidomide have also shown that it has no effect on any of p450 cytochrome enzymes [23].

Pomalidomide is a treatment option after lenalidomide and bortezomib in relapsed/refractory MM. Literature data on the drug-drug interaction (DDI) potential of pomalidomide is very limited. Pomalidomide clearance is mediated by hydrolysis and cytochrome p450-mediated hydroxylation. In an important study on DDI of pomalidomide [24], its relationship with the p450 system was investigated. Co-administration of oral
Table 5 Multivariate analysis of MM patients (Cox regression)

\begin{tabular}{|c|c|c|c|c|c|c|}
\hline & $\operatorname{Exp}(\mathrm{B})$ & $\begin{array}{l}\text { OS } \\
95 \% \mathrm{CI}\end{array}$ & $p$ & $\operatorname{Exp}(\mathrm{B})$ & $\begin{array}{l}\text { PFS } \\
95 \% \text { CI }\end{array}$ & $p$ \\
\hline & $\begin{array}{l}\text { Relative } \\
\text { risk }\end{array}$ & & & $\begin{array}{l}\text { Relative } \\
\text { risk }\end{array}$ & & \\
\hline IPI I/II-III & 5.011 & $0.477-56.210$ & 0.191 & 1.120 & $0.346-3.621$ & 0.850 \\
\hline Age $<65 \geq 65$ & 27.988 & $2.616-299.799$ & 0.006 & 4.496 & $1.305-15.493$ & 0.017 \\
\hline $\begin{array}{l}C Y P 3 A 4 * 1 B \\
\quad N N / M M-M N\end{array}$ & 0.024 & $0.002-0.313$ & 0.004 & 0.318 & $0.113-0.895$ & 0.030 \\
\hline
\end{tabular}

Data written in bold was found to be statistically significant $(p<0.05)$

**IPI International Prognostic Index, PFS progression-free survival, $O S$ overall survival 


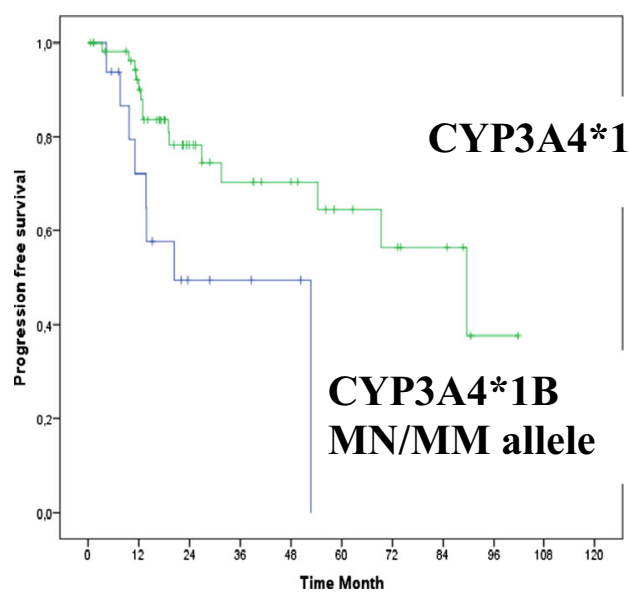

$\operatorname{Cox} \mathrm{p}=0.030$

Fig. 1 Kaplan-Meier analysis - progression-free survival (PFS)

(4 mg/day) pomalidomide with ketoconazole (a CYP3A inhibitor) or carbamazepine (a CYP3A inducer) did not cause clinically significant changes in the exposure to pomalidomide. Co-administration of pomalidomide with fluvoxamine (a CYP1A2 inhibitor) in the presence of ketoconazole approximately doubled the exposure of pomalidomide. Pomalidomide appears to have a low potential for clinically relevant DDI and is unlikely to affect clinical exposure of other drugs. It is recommended that the concomitant administration of strong CYP1A2 inhibitors should be avoided unless medically necessary and the dose of pomalidomide be reduced by $50 \%$ when administered with strong CYP1A2 inhibitors and strong CYP3A inhibitors [24].

Carfilzomib, an irreversible proteasome inhibitor, has a favorable safety profile and significant anti-tumor activity in relapsed and refractory MM. In a study about DDI of carfilzomib [25], the clinical pharmacokinetics (PK), metabolism, and DDI profile of carfilzomib are summarized. Carfilzomib has been found to be largely extrahepatically cleared by peptidase cleavage and epoxide hydrolysis. Cytochrome P450-mediated metabolism played a minor role, suggesting that co-administration of p450 inhibitors or inducers is unlikely to alter the PK profile. When we examine the results of our patients and the relationship between these two drugs, it is necessary to start by emphasizing that significantly more PD rescue regimen was used in patients with the CYP3A4*1B NN genotype. Although pomalidomide p450mediated DDI data are quite limited, the significantly better OS in this patient group in our study is a very important clinical finding and contribution to the literature.

In the light of this information, it is possible to say that there are three agents that can play a role in CYP3A4 polymorphism and treatment responses that form the basis of our study: bortezomib, cyclophosphamide, and pomalidomide.

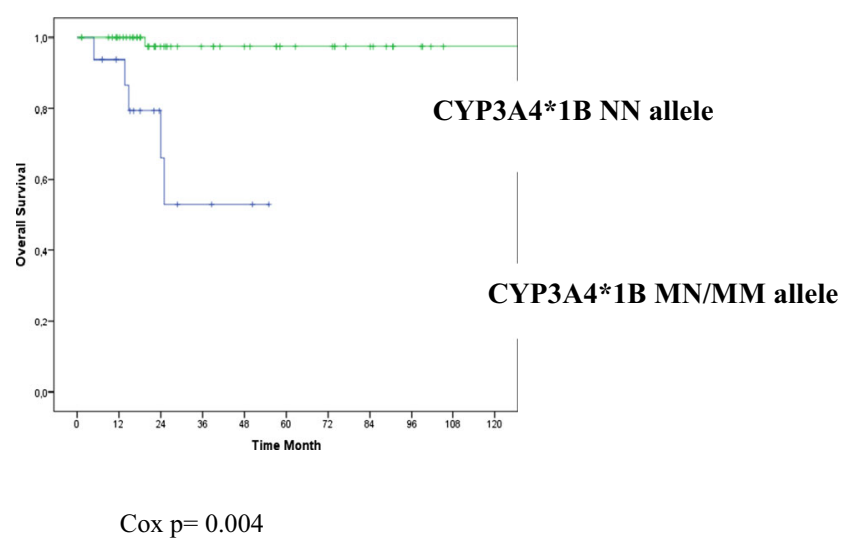

Fig. 2 Kaplan-Meier analysis — overall survival (OS)

Our study's results are promising in the sense that they may guide new studies to be planned with these agents. Our study also had limitations. It can be said that the most important limitation is that we have a narrow patient population. A study plan in which drug responses mentioned in the discussion and thought to affect OS and PFS fundamentally can be examined separately will also contribute to the literature. In addition, it will be useful to investigate the effects of prophylactic antibiotherapy or antifungals used during treatment and to examine the relationship with CYP3A4 separately. In addition, differences in regimens used after progression and not being suitable for statistical analysis after first line of rescue regimens are other limitation points.

As a result, this study demonstrated that CYP3A4*1B NN genotype, which is an important cytochrome 450 member for the treatment of MM, was 41.666-fold protective for OS and 3.144-fold protective for PFS. It was shown in this study for the first time in the literature as a valuable contribution. It is thought to be a guide for a study in which larger patient groups and drug sub-analyzes can be performed.

Acknowledgments We respectfully remember all the colleagues we lost in the COVID-19 fight.

Authors' contributions All authors contributed to the editing of the manuscript. IS wrote the manuscript and made tables.

Data availability The authors declare that data supporting the findings of this study are available within the referenced articles.

\section{Compliance with ethical standards}

Conflict of interest The authors declare that they have no conflict of interest.

Ethics approval and consent to participate Ethical committee approval was received (approval date and number: 07-2007/40), and the patients and control subjects gave informed consent before the beginning of the study. The experimental procedures were based on the Declaration of Helsinki and relevant institutional regulations. 
Patient consent for publication An informed consent was obtained as written forms from all of our patients to publish.

Abbreviations MM, multiple myeloma; PET/CT, positron emission tomography/computed tomography; MR, magnetic resonance; CT, computed tomography; OS, overall survival; PFS, progression-free survival; IPI, International Prognostic Index; ECOG, Eastern Cooperative Oncology Group; LDH, lactate dehydrogenase; CRP, C-reactive protein; ASCT, autologous stem cell transplantation; VCD, bortezomib, cyclophosphamide, and dexamethasone; LD, lenalidomide, dexamethasone; SNP, single nucleotide polymorphism; DDI, Drug-drug interaction; PK, Pharmacokinetic; CYP, The cytochrome $\mathrm{p} 450$ system; PCR, polymerase chain reaction

\section{References}

1. Rajkumar SV, Dimopoulos MA, Palumbo A, Blade J, Merlini G, Mateos MV et al (2014) International Myeloma Working Group updated criteria for the diagnosis of multiple myeloma. Lancet Oncol. 15(12):e538-e548. https://doi.org/10.1016/S14702045(14)70442-5

2. Siegel RL, Miller KD, Jemal A (2019) Cancer statistics, 2019. CA Cancer J Clin. 69(1):7-34. https://doi.org/10.3322/caac.21551

3. Palumbo A, Anderson K (2011) Multiple myeloma. N Engl J Med. 364(11):1046-1060. https://doi.org/10.1056/NEJMra1011442

4. Kazandjian D (2016) Multiple myeloma epidemiology and survival: a unique malignancy. Semin Oncol. 43(6):676-681. https://doi. org/10.1053/j.seminoncol.2016.11.004

5. Alzahrani AM, Rajendran P (2020) The multifarious link between cytochrome P450s and cancer. Oxid Med Cell Longev. 2020: 3028387. https://doi.org/10.1155/2020/3028387

6. Guengerich FP, Waterman MR, Egli M (2016) Recent structural insights into cytochrome P450 function. Trends Pharmacol Sci. 37(8):625-640. https://doi.org/10.1016/j.tips.2016.05.006

7. Nelson DR, Koymans L, Kamataki T, Stegeman JJ, Feyereisen R, Waxman DJ, Waterman MR, Gotoh O, Coon MJ, Estabrook RW, Gunsalus IC, Nebert DW (1996) P450 superfamily: update on new sequences, gene mapping, accession numbers and nomenclature. Pharmacogenetics. 6(1):1-42. https://doi.org/10.1097/00008571199602000-00002

8. Nelson DR, Zeldin DC, Hoffman SM, Maltais LJ, Wain HM, Nebert DW (2004) Comparison of cytochrome P450 (CYP) genes from the mouse and human genomes, including nomenclature recommendations for genes, pseudogenes and alternative-splice variants. Pharmacogenetics 14(1):1-18

9. Manikandan P, Nagini S (2018) Cytochrome P450 structure, function and clinical significance: a review. Curr Drug Targets. 19(1): 38-54. https://doi.org/10.2174/1389450118666170125144557

10. Lolodi O, Wang YM, Wright WC, Chen T (2017) Differential regulation of CYP3A4 and CYP3A5 and its implication in drug discovery. Curr Drug Metab. 18(12):1095-1105. https://doi.org/ $10.2174 / 1389200218666170531112038$

11. Kacevska M, Ivanov M, Wyss A, Kasela S, Milani L, Rane A, Ingelman-Sundberg M (2012) DNA methylation dynamics in the hepatic CYP3A4 gene promoter. Biochimie. 94(11):2338-2344. https://doi.org/10.1016/j.biochi.2012.07.013

12. Kuehl P, Zhang J, Lin Y, Lamba J, Assem M, Schuetz J, Watkins PB, Daly A, Wrighton SA, Hall SD, Maurel P, Relling M, Brimer C, Yasuda K, Venkataramanan R, Strom S, Thummel K, Boguski MS, Schuetz E (2001) Sequence diversity in CYP3A promoters and characterization of the genetic basis of polymorphic CYP3A5 expression. Nat Genet. 27(4):383-391. https://doi.org/10.1038/86882
13. Rebbeck TR, Jaffe JM, Walker AH, Wein AJ, Malkowicz SB (1998) Modification of clinical presentation of prostate tumors by a novel genetic variant in CYP3A4. J Natl Cancer Inst 90(16): 1225-1229. https://doi.org/10.1093/jnci/90.16.1225 Erratum in: J Natl Cancer Inst 1999 Jun 16;91(12):1082

14. Klein K, Zanger UM (2013) Pharmacogenomics of cytochrome P450 3A4: recent progress toward the "missing heritability" problem. Front Genet. 4:12. https://doi.org/10.3389/fgene.2013.00012

15. Paris PL, Kupelian PA, Hall JM, Williams TL, Levin H, Klein EA, Casey G, Witte JS (1999) Association between a CYP3A4 genetic variant and clinical presentation in African-American prostate cancer patients. Cancer Epidemiol Biomarkers Prev. 8(10):901-905

16. Basseville A, Preisser L, de Carné Trécesson S et al (2011) Irinotecan induces steroid and xenobiotic receptor (SXR) signaling to detoxification pathway in colon cancer cells. Mol Cancer 10:80. https://doi.org/10.1186/1476-4598-10-80

17. Luckert C, Ehlers A, Buhrke T, Seidel A, Lampen A, Hessel S (2013) Polycyclic aromatic hydrocarbons stimulate human CYP3A4 promoter activity via PXR. Toxicol Lett 222(2):180-188

18. Tan CRC, Abdul-Majeed S, Cael B, Barta SK (2019) Clinical pharmacokinetics and pharmacodynamics of bortezomib. Clin Pharmacokinet. 58(2):157-168. https://doi.org/10.1007/s40262018-0679-9

19. Hellmann A, Rule S, Walewski J, Shpilberg O, Feng H, van de Velde H, Patel H, Skee DM, Girgis S, Louw VJ (2011) Effect of cytochrome P450 3A4 inducers on the pharmacokinetic, pharmacodynamic and safety profiles of bortezomib in patients with multiple myeloma or non-Hodgkin's lymphoma. Clin Pharmacokinet. 50(12):781-791. https://doi.org/10.2165/11594410-00000000000000

20. Yang L, Yan C, Zhang F, Jiang B, Gao S, Liang Y, Huang L, Chen W (2018) Effects of ketoconazole on cyclophosphamide metabolism: evaluation of CYP3A4 inhibition effect using the in vitro and in vivo models. Exp Anim. 67(1):71-82. https://doi.org/10.1538/ expanim.17-0048

21. Kuczma M, Ding ZC, Zhou G (2016) Immunostimulatory Effects of Melphalan and Usefulness in adoptive cell therapy with antitumor CD4+ T cells. Crit Rev Immunol. 36(2):179-191. https://doi. org/10.1615/CritRevImmunol.2016017507

22. Nath CE, Shaw PJ, Trotman J, Zeng L, Duffull SB, Hegarty G, McLachlan AJ, Gurney H, Kerridge I, Kwan YL, Presgrave P, Tiley C, Joshua D, Earl J (2010) Population pharmacokinetics of melphalan in patients with multiple myeloma undergoing high dose therapy. Br J Clin Pharmacol. 69(5):484-497. https://doi.org/10. 1111/j.1365-2125.2010.03638.x

23. Chen N, Zhou S, Palmisano M (2017) Clinical pharmacokinetics and pharmacodynamics of lenalidomide. Clin Pharmacokinet. 56(2):139-152. https://doi.org/10.1007/s40262-016-0432-1

24. Kasserra C, Assaf M, Hoffmann M, Li Y, Liu L, Wang X et al (2015) Pomalidomide: evaluation of cytochrome P450 and transporter-mediated drug-drug interaction potential in vitro and in healthy subjects. J Clin Pharmacol. 55(2):168-178. https://doi. org $/ 10.1002 / j$ cph. 384

25. Wang Z, Yang J, Kirk C, Fang Y, Alsina M, Badros A et al (2013) Clinical pharmacokinetics, metabolism, and drug-drug interaction of carfilzomib. Drug Metab Dispos. 41(1):230-237. https://doi.org/ $10.1124 / \mathrm{dmd} .112 .047662$

Publisher's note Springer Nature remains neutral with regard to jurisdictional claims in published maps and institutional affiliations. 